\title{
Silymarin content in Silybum marianum extracts as a biomarker for the quality of commercial tinctures
}

\begin{abstract}
Silybum marianum (L.) Gaertner (Milk thistle) extracts have been widely used for the treatment of liver pathologies and as a hepatoprotectant against alcohol-induced liver diseases and other harmful drug metabolites or toxins. Silymarin, the active fraction of Silybum marianum tinctures, accounts for $70-80 \%$ of the plants hydro-alcoholic extract and consists of a mixture of flavonolignans and a flavonoid. Silybum marianum tinctures are commonly prescribed by herbal practitioners for the treatment of liver diseases. However, previous studies have showed inconsistency in the therapeutic efficacy of Silybum marianum tinctures, which is believed to have arisen from the content variability of silymarin, resulting from lack of standardized and regulated manufacturing processes. This work was conducted to quantify the silymarin content in commercial Silybum marianum tinctures in order to evaluate their quality. In this study, we report the determination of the total silymarin content in eleven different commercial tinctures produced in the U.K. using a convenient and accurate HPLC-UV method. The tinctures analyzed differed in the ratio between herb and liquid as well as percentage of ethanol used during the extraction process. Our results showed a direct correlation between the silymarin content in tinctures and the alcohol strength. Following our protocol, silymarin could not be detected in tinctures extracted with $25 \%$ ethanol. Effective therapeutic doses were found only in tinctures with a concentration ratio herb to liquid $1: 1(\mathrm{~kg} / \mathrm{L})$ and an alcoholic content of $70 \%$. To guarantee quality and safety of herbal medicinal products, legal requirements to produce plant-based products under regulatory frameworks are needed.
\end{abstract}

Key words: Silymarin, Silybum marianum, HPLC, alcoholic extracts, quality control, biomarker

\section{Introduction}

Silybum marianum (L.) Gaertner (milk thistle) is a spiny annual or biennial plant, native to the Mediterranean but found growing throughout Europe. Traditionally the plant extract has been used for a variety of acute and chronic liver diseases. The crude hydro-alcoholic extract of crushed seeds (achene, Fructus silybi) that develop from the plant's purple flowers contains from $65 \%$ to $80 \%$ of silymarin, whereas the remaining $35 \%$ to $20 \%$ accounts for uncharacterized polyphenols and fatty acids, 
including linoleic, oleic and palmitic acids. Silymarin is widely considered to be the principal active fraction in milk thistle tinctures, and is known to be primarily a mixture of a variety of flavonolignans and the flavonoid taxifolin. The main flavonolignans identified in silymarin are reported in Fig. 1.

Clinical trials using silymarin preparations have provided support for its traditional use as a hepatoprotective agent, showing both a protective and curative effect in the treatment of acute and chronic hepatitis, alcohol-related liver diseases and liver damage resulting from highly toxic compounds, including from the death cap mushroom Amanita phalloides (Blumenthal, 2000; Fraschini et al., 2002). In vitro anti-inflammatory, anti-arthritic, antioxidant and anti-carcinogenic properties have also been documented (Gupta et al., 2000; Pendry et al., 2006; Shaker et al., 2010; Zhao et al., 2011; Agarwal et al., 2013) as well as clinical trials testing silymarin in cancer therapy (Invernizzi et al., 1993; Schröder, F.H. et al., 2005; Greenlee, H. et al., 2007; Shahbazi, F. et al., 2015; Elyasi, S. et al., 2016).

Tinctures are the most widely applied pharmaceutical form of plant medicine among herbal practitioners. Currently, tincture manufacturers are not legally required to regulate their products under any regulatory frameworks in order to assure quality and safety of botanicals. As a consequence, the majority of the herbal medicines and food supplements are still sold as unlicensed products. This causes difficulties for herbal practitioners and consumers to distinguish between high- and low-quality products, as well as unreliability in dosage and treatments outcomes.

Previous studies have shown that silymarin content variability has led to inconsistent therapeutic efficacy of Silybum marianum (Saller et al., 2001; Rambaldi et al., 2005). According to Bone (2003), aqueous ethanol extracts of Silybum marianum should contain not less than $25 \mathrm{mg} / \mathrm{mL}$ silymarin, and a therapeutic dose of 4.5-8.5 mL of $1: 1$ liquid extract accounting for a total uptake of $113-213 \mathrm{mg} /$ day of silymarin is recommended for the treatment of hepatitis and liver-associated diseases. This therapeutic guideline was further supported by clinical studies into the therapeutics benefits of silymarin, where a dose-response window of 200-400 mg per day was identified (Wichtl, 2004).

The aim of this study was to quantify the silymarin content in commercial Silybum marianum tinctures in order to verify whether these products ensured both consistency of quality and dosage, and made treatment outcomes easier to evaluate. Eleven different Silybum marianum tinctures commercially available in the U.K. were tested using a convenient and accurate HPLC-UV analytical method. Ultimately, this study aims to provide herbal practitioners and consumers with a better understanding 
of the quality of commercial tinctures as well as to help manufacturers gain and maintain their trustworthiness in the tinctures market.

\section{Materials and Methods}

Reference standard for silymarin (mixture of flavonolignans) purchased from Sigma-Aldrich (Steinheim, Germany) catalogue no. S0292. Methanol (Assay (GC) of 99.99\%) and ethanol (99.7\% - 100\%) were HPLC grade (Fisher Scientific UK Ltd). Glacial acetic acid (min. 99.8\%) was analytical grade (AnalaR ${ }^{\circledR} \mathrm{DBH}$ Laboratories Supplies, Poole, England). Water was purified in the laboratory with an ELGA water purification system (model OPTION-S 15BP).

The HPLC system was composed of a Perkin-Elmer Model Series 410 Liquid Chromatograph gradient pump (USA), a Hewlett Packard Series 1050 auto sampler (USA), and a Varian 2550 Variable $\lambda$ UV detector (USA). The HPLC system was controlled, data integrated and evaluated by a Windows 98 PC operating Perkin Elmer TotalChrom software for chromatography, which communicated with the UV detector through a Perkin Elmer NC1900 Interface. The mobile phase was degassed prior to use with an ultrasonic bath by Kerry Ultrasonic Ltd.

\subsection{Tinctures}

Tinctures of Silybum marianum were purchased from eight manufacturers commonly used by herbal practitioners in the U.K. The samples, eleven in all, were randomly labelled $\mathrm{A}-\mathrm{K}$ and their identity was not known until after the analyses were complete (Table 1).

\subsection{Standard and sample preparation}

A stock solution of silymarin was prepared in methanol at a concentration of 1 $\mathrm{mg} / \mathrm{mL}$, and serial dilutions were made to obtain standard concentrations at the following concentrations: $0.65,0.5,0.25,0.125,0.02 \mathrm{mg} / \mathrm{mL}$. Samples were stored at $4^{\circ} \mathrm{C}$ (storage time 3 months). Commercial tinctures were prepared by diluting $50 \mu \mathrm{L}$ of the tincture with $950 \mu \mathrm{L}$ of methanol and the resulting dilution centrifuged at 13000

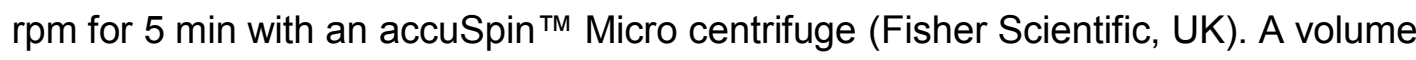
of $200 \mu \mathrm{L}$ of the supernatant was placed into HPLC vials and a $20 \mu \mathrm{L}$ aliquot injected onto the HPLC column for each analysis. All analysis were made in triplicate.

\subsection{Chromatography conditions}


Separations were achieved using a Luna $5 \mu \mathrm{m}$ C18 100R reversed phase column (Phenomenex ${ }^{\circledR}$ Ltd UK) of $150 \times 4.60 \mathrm{~mm}$ i.d. The column was equipped with a Phenomenex SecurityGuard ${ }^{\mathrm{TM}} \mathrm{C} 18$ cartridge ( $4 \mathrm{~mm} \times 3.0 \mathrm{~mm}$ i.d). The flow rate was $1 \mathrm{~mL} / \mathrm{min}$ using a gradient mobile phase of $2 \%$ acetic acid $(A)$ and methanol /water/acetic acid (18:1:1\% v/v) (B). The starting mobile phase was 75:25 A:B increased to $100 \% \mathrm{~B}$ in a linear gradient over $20 \mathrm{~min}$, held for $4 \mathrm{~min}$ and returned in 1 min to $75: 25$ for the next injection. UV detection of calibration and tincture samples were monitored at $285 \mathrm{~nm}$ and data processed by Totalchrom software.

\section{Results}

\subsection{Validation procedure}

A set of six standard solutions of silymarin was prepared in methanol at concentrations ranging from $1 \mathrm{mg} / \mathrm{mL}$ to $0.02 \mathrm{mg} / \mathrm{mL}$. Figure 2 represents the characteristic chromatographic profile of a standardized silymarin extract (Bilia et al., 2001; Lee et al., 2007; Liu et al., 2009), where a double cluster of peaks from 12-14 and 16-18 min is still identifiable at the lowest concentration of $0.02 \mathrm{mg} / \mathrm{mL}$. Liu et al (2009) identified the 2 peaks of the first cluster as silychristin and isosilychristin plus silidianin, respectively, and the first 2 peaks of the second cluster as silybin A plus $B$ with the remaining 2 major peaks as isosilybin A plus B. Although the peaks are unresolved to base line (as Quaglia et al 1999 found for some peaks), the calibration curve was constructed by plotting the sum of the peak area corresponding to the seven flavonolignans and taxifolin $\left(t_{r}=9.33 \mathrm{~min}\right)$ against the concentration using a linear regression analysis $\left(R^{2}=0.99\right)$. Graf et al. (2016) investigated the potential matrix effect which is typical of natural product extracts by using and comparing HPLC-UV and LC-MS methods. The authors demonstrated that both detections were effective in quantifying silymarin extracts, and that matrix effect was negligible remarking that MS and UV are both valid techniques for the quantification of silymarin mixture. Since herbal practitioners prescribe therapeutic doses of Silybum marianum tincture based on silymarin content, herein we reported our results as the total content of silymarin expressed as $\mathrm{mg} / \mathrm{mL}$. The silymarin concentration $(\mathrm{mg} / \mathrm{mL})$ in tinctures was calculated using the sum of the peak area corresponding to the seven main flavonolignans and taxifolin.

\subsection{Limit of Detection and Limit of Quantitation}

The limit of detection (LOD) based on a signal-to-noise ratio ( $\mathrm{S} / \mathrm{N}: 3)$ was 0.08 $\mu \mathrm{g} / \mathrm{mL}$. The limit of quantitation (LOQ) based on the signal-to-noise ratio (S/N: 10) 
using the lowest concentration in the calibration curve and the highest noise observed when injecting a blank was $0.25 \mu \mathrm{g} / \mathrm{mL}$ (Rosing et al., 2000). For a $20 \mu \mathrm{L}$ sample injection, these correspond to $1.6 \mathrm{ng}$ (LOD) and $5.2 \mathrm{ng}$ (LOQ).

\subsection{Accuracy and precision}

The intraday coefficient of variation (\%CV) was calculated for the retention times and peak areas for all injections per sample (x 3). The \%CV was deemed acceptable at $<5 \%$ for peak areas and $<1 \%$ for retention times. The analytical data shown for the commercial tinctures indicate the accuracy and confidence of the reported method (Rosing et al, 2000).

\subsection{Herbal Tinctures Formulations}

Silymarin content was determined in eleven commercial tincture products (A-K) produced by eight different manufactories in the U.K. (Table 1). Samples differed in the ratio between the dry herb weight and the solvent volume $(\mathrm{kg} / \mathrm{L})$ and in the percentage of ethanol used during the extraction process. Sample J, produced by using $70 \%$ of ethanol content during the extraction process, recorded the highest concentration of silymarin $(18.37 \pm 0.25 \mathrm{mg} / \mathrm{mL}$ ). Whilst samples $\mathrm{E}, \mathrm{F}$ and I (alcoholic percentage between $45-51 \%)$ showed a moderate silymarin content $(4.75 \pm 0.17$ $\mathrm{mg} / \mathrm{mL}, 4.54 \pm 0.35 \mathrm{mg} / \mathrm{mL}$ and $5.02 \pm 0.11 \mathrm{mg} / \mathrm{mL}$ respectively), the amount of silymarin could not be quantified in all the remaining samples, which were extracted with $25 \%$ of alcohol. Figure 3 depicted the chromatographic profile of samples $\mathrm{J}$ and $\mathrm{E}$, where all the characteristic silymarin peaks are distinguishable (Figure $3 \mathrm{a}$ and $3 \mathrm{~b}$, respectively), and sample $D$, where none of the typical cluster patterns can be identified (Figure 3c).

\section{Discussion}

This work was part of a quality control study on commercial tinctures of Silybum marianum, and reflects previous work in our laboratory demonstrating the extent of the variation in the biomarker content of commercially available herbal medicines (Sanchez-Medina et al., 2007; Gao et al., 2008). By developing a suitable HPLC-UV method, we demonstrated significant differences in chemical composition and variability among Silybum marianum tinctures. The results of silymarin analysis in the commercial tincture products show a clear pattern between silymarin concentration and alcohol strength with increasingly higher amounts detected as the ethanol ratio 
increased (Table 1). These results appear to support the results of Bilia et al. (2001) who detected considerably lower flavonolignan levels in a $40 \% \mathrm{v} / \mathrm{v}$ Silybum marianum tincture compared with $60 \% \mathrm{v} / \mathrm{v}$. According to Bone (2003), the suggested daily dose of a Silybum marianum tincture $(70 \%, 1: 1)$ is $4.5-8.5 \mathrm{~mL}$ containing not less than $25 \mathrm{mg} / \mathrm{mL}$ silymarin. Our data shows that of eleven commercial tincture products, only $\mathrm{J}$ could be reasonably administered following the recommended daily dose of $8 \mathrm{~mL}$ per day (Table 1); whereas for sample $\mathrm{E}, \mathrm{F}$ and I, a daily dose of 150 $\mathrm{mg}$ (median daily dose) silymarin would correspond to approximately $30 \mathrm{~mL}$ of tincture daily. Remarkably, all the tinctures extracted with $25 \%$ were far from satisfying this therapeutic guideline at any ratio between the dry herb weight and the solvent volume.

The majority of trials investigating the therapeutic potential of Silybum marianum have been carried out using extracts standardized to contain at least $70 \%$ silymarin. Our data showed that the majority of the samples investigated had poor phytochemical quality as they were far from meeting this concentration. Despite their popularity as an herbal medicine, Silybum marianum tinctures may provide an unsuitable dosage of silymarin unless standardized to the recommended silymarin concentrations $(\mathrm{mg} / \mathrm{mL})$. To guarantee both consistency of quality and dosage, and make treatment outcomes easier to evaluate, a legal requirement for herbal medicinal producers to comply with a regulatory framework should be considered.

\section{Conclusion}

The current study aimed to determine the silymarin content in Silybum marianum tinctures produced by eight different retailers in the U.K. This HPLC method proved to be an invaluable tool for the analysis of silymarin in hydro-alcoholic extracts. The authors demonstrated that extraction processes of silymarin involving less than $45 \%$ of alcohol is unsuitable for therapeutic uses as the silymarin content was negligible. Low levels of silymarin were also detected in tinctures extracted with $45-50 \%$ ethanol. To ensure effective treatment outcomes, the use of tinctures with a concentration ratio herb to liquid $1: 1(\mathrm{~kg} / \mathrm{L})$ and an alcoholic content of $70 \%$ is strongly recommended.

\section{References}


Agarwal, C., Wadhwa, R., Deep, G., Biedermann, D., Gažák, R., Křen, V., Agarwal, R., 2013. Anti-cancer efficacy of silybin derivatives-a structure-activity relationship. PLOS one 8(3), e60074.

Bilia, A.R., Salvini, D., Mazzi, G., Vincieri, F.F., 2001. Characterization of Calendula flower, milk-thistle fruit, and passion flower tinctures by HPLC-DAD and HPLC-MS. Chromatographia. 53 (3/4), 210-215.

Blumenthal, M. (ed.)., 2000. Herbal Medicine Expanded Commission E Monographs. American Botanical Council, Austin, pp 257-263.

Bone, K., 2003. A Clinical Guide to Blending Liquid Herbs: Herbal Formulations for the Individual Patient. Churchill Livingstone, Edinburgh, pp. 326-328.

Elyasi, S., Hosseini, S., Niazi Moghadam, M.R., Aledavood, S.A., Karimi, G., 2016. Effect of oral silymarin administration on prevention of radiotherapy induced mucositis: a randomized, double-blinded, placebo-controlled clinical trial. Phytother. Res. 30(11), 1879-1885

Fraschini, F., Demartini, G., Esposti, D., 2002. Pharmacology of Silymarin. Clin. Drug Invest. 22(1), 51-65.

Gao, J., Sanchez-Medina, A., Pendry, B.A., Hughes, M.J., Webb, G.P., Corcoran, O., 2008. Validation of a HPLC method for flavonoid biomarkers in skullcap (Scutellaria) and its use to illustrate wide variability in the quality of commercial tinctures. J. Pharm. Pharmaceut. Sci. 11 (1), 77-87.

Greenlee, H., Abascal, K., Yarnell, E., Ladas, E., 2007. Clinical applications of Silybum marianum in oncology. Integr. Cancer Ther. 6, 158-165.

Graf, T.N., Cech, N.C., Polyak, S.J., Oberlies, N.H., 2016. A validated UHPLCtandem mass spectrometry method for quantitative analysis of flavonolignans in milk thistle (Silybum marianum) extracts. J. Pharm. Biomed. Anal. 126, 26-33.

Gupta, O.P., Sing, S., Bari, S., Sharma, N., Malhotra, S., Gupta, B.D., Banerjee, S.K., Handa, S.S., 2000. Anti-inflammatory and anti-arthritic activities of silymarin acting through inhibition of 5-lipoxygenase. Phytomedicine. 5(1), 21-24.

Invernizzi, R, Bernuzzi, S, Ciani, D, Ascari, E., 1993. Silymarin during maintenance therapy of acute promyelocytic leukemia. Haematologica 78, 340-341.

Lee. J., Narayan, M., Barrett, J, 2007. Analysis and comparison of active constituents in commercial standardized silymarin extracts by liquid chromatography-electrospray ionization mass spectrometry. J. Chromatogr B. 845, 95-103. 
Liu, H., Du, Z.U., Yuan, Q., 2009. A novel rapid method for simultaneous determination of eight active compounds in silymarin using a reversed-phase UPLCUV detector. J. Chromatogr B. 877, 4159-4163.

Pendry, B.A., Busia, K., Bell, C., 2006. Phytochemical analysis of the antioxidant properties of Silybum marianum L. Oriental Pharmacy and Experimental Medicine. 6(3), 167-173.

Quaglia, M.G., Bossu, E., Donati, E., Mazzanti, G., Brandt, A., 1999. Determination of silymarine in the extract from the dried silybum marianum fruits by high performance liquid chromatography and capillary electrophoresis. J. Pharm. Biomed Anal. 19, 435-442.

Rambaldi, A., Jacobs, B.P., laquinto, G., Gluud, C., 2005. Milk thistle for alcoholic and/or hepatitis $B$ or $C$ liver diseases-a systematic cochrane hepato-biliary group review with meta-analyses of randomized clinical trials. Am J Gastroenterol. 100(11), 2583-91.

Rosing, H., Man, W. Y., Doyle, E., Bult, A and Beijnen, J. H., 2000. Bioanalytical liquid chromatographic method validation. A review of current practices and procedures. J. Liq. Chromatogr. Relat. Technol. 23, 329-354.

Saller, R., Meier, R., Brignoli, R., 2001. The use of silymarin in the treatment of liver diseases. Drugs. 61(14), 2035-2063.

Sanchez-Medina, A., Etheridge, C.J., Hawkes, G.E., Hylands, P.J., Pendry, B.A., Hughes, M.J. and Corcoran, O, 2007. Comparison of rosmarinic acid content in commerical tinctures produced from fresh and dried lemonbalm (Melissa officinalis). J. Pharm. Pharm. Sci. 10(4), 455-463.

Schröder, F.H., Roobol, M.J., Boevé, E.R., de Mutsert, R., Zuijdgeest-van Leeuwen, S.D., Kersten, I., Wildhagen, M.F., van Helvoort, A., 2005. Randomized, doubleblind, placebo-controlled crossover study in men with prostate cancer and rising PSA: effectiveness of a dietary supplement. Eur. Urol. 48, 922-930.

Shahbazi, F., Sadighi S., Dashti-Khavidaki, S., Shahi, F., Mirzania, M., Abdollahi, A., Ghahremani, M.H., 2015. Effect of silymarin administration on cisplatin nephrotoxicity: report from a pilot, randomized, double-blinded, placebo-controlled clinical trial. Phytother. Res. 29(7), 1046-53.

Shaker, E., Mahmoud, H., Mnaa, S., 2010. Silymarin, the antioxidant component and Silybum marianum extracts prevent liver damage. Food Chem. Toxicol. 48, 803-806. 
Wichtl, M, 2004. Herbal Drugs and Phytopharmaceuticals: A Handbook For Practice On A Scientific Basis, $3^{\text {rd }}$ Ed., Medpharm Scientific Publishers, Stuttgart, pp 108-111. Zhao, H. Brandt, G.E., Galam, L., Matts, R.L. Blagg, B.S.J., 2011. Identification and initial SAR of silybin: An Hsp90 inhibitor. Bioorg. Med. Chem. Lett. 21, 2659-2664. 
Table 1.

Silymarin content, expressed as $\mathrm{mg} / \mathrm{mL}$, in commercial tincture samples produced with different ethanol-water ratio extraction processes and the corresponding volume required to reach a suggested therapeutic dose of 150 mg/day (median daily dose).

\begin{tabular}{llccc}
\hline \multicolumn{2}{c}{ Sample $^{a}$} & $\begin{array}{c}\text { \% ethanol in } \\
\text { water }^{b}\end{array}$ & $\begin{array}{c}\text { Silymarin } \\
(\mathbf{m g} / \mathbf{m L} \pm \text { SD })\end{array}$ & $\begin{array}{c}\text { mL/day required for a } \\
\text { therapeutic dose }^{c}\end{array}$ \\
\hline A & $(1: 1)$ & 25 & ND & - \\
B $\quad(1: 5)$ & 25 & ND & - \\
C $\quad(1: 3)$ & 25 & ND & - \\
D $\quad(1: 1)$ & 25 & ND & - \\
E $\quad(1: 1.33)$ & 51 & $4.75 \pm 0.17$ & 31.5 \\
F & $(1: 3)$ & 45 & $4.54 \pm 0.35$ & 33.0 \\
G $\quad(1: 1)$ & 25 & ND & - \\
H $\quad(1: 3)$ & 25 & ND & - \\
I $(1: 1)$ & 45 & $5.02 \pm 0.11$ & 30.0 \\
J $\quad(1: 1)$ & 70 & $18.37 \pm 0.25$ & 8.2 \\
K $\quad(1: 3)$ & 25 & ND & - \\
\hline
\end{tabular}

${ }^{a}$ In brackets concentration ratio herb to liquid $(\mathrm{kg} / \mathrm{L})$ and ${ }^{b}$ percentage of ethanol used during the extraction process of the commercial tinctures. ${ }^{c}$ Amount of tincture expresses as $\mathrm{mL} /$ day required to reach a therapeutic dose of $150 \mathrm{mg}$, extrapolated from the determined silymarin concentration $(\mathrm{mg} / \mathrm{mL}) . \mathrm{ND}=$ not detected 
<smiles>COc1cc([C@H]2Oc3cc([C@H]4Oc5cc(O)cc(O)c5C(=O)[C@H]4O)ccc3O[C@@H]2CO)ccc1O</smiles>

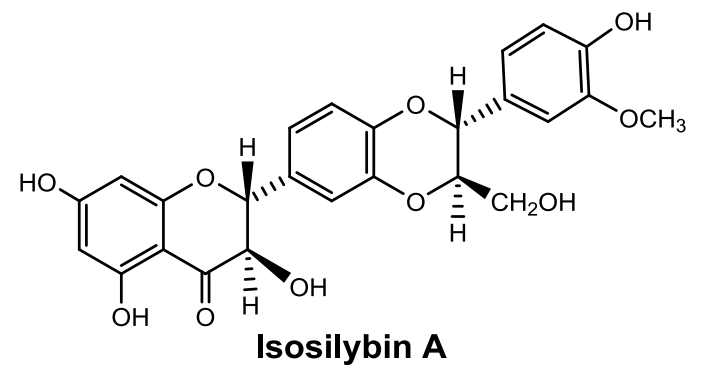<smiles>COc1cc(C2Oc3c(O)cc([C@H]4Oc5cc(O)cc(O)c5C(=O)[C@H]4O)cc3[C@H]2CO)ccc1O</smiles>

Silychristin

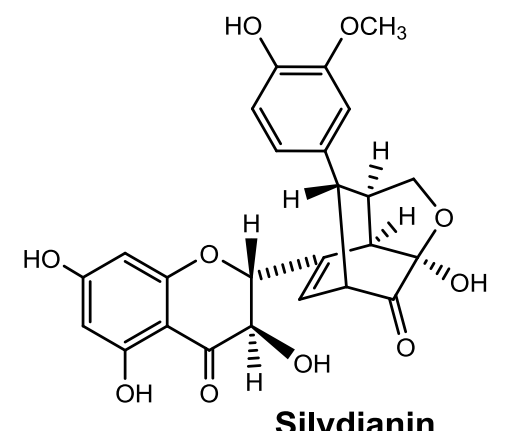<smiles>COc1cc([C@H]2Oc3cc([C@H]4Oc5cc(O)cc(O)c5C(=O)[C@H]4O)ccc3O[C@H]2CO)ccc1O</smiles>

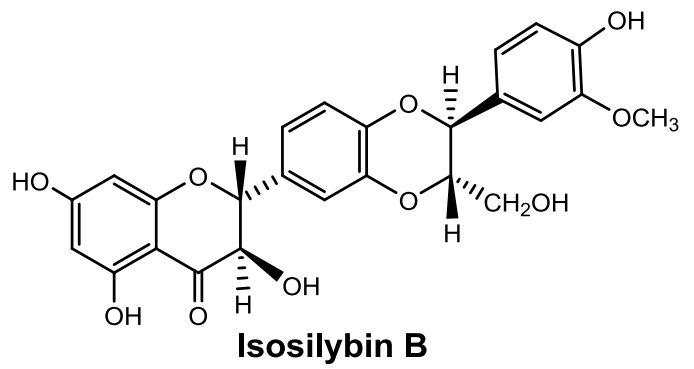<smiles>COc1cc([C@H]2Oc3c(O)ccc4c3[C@@H](CO)[C@H]4Oc3cc(O)cc(O)c3C2=O)ccc1O</smiles><smiles>O=C1c2c(O)cc(O)cc2O[C@H](c2ccc(O)c(O)c2)[C@H]1O</smiles>

Fig 1. Chemical structure of the flavonoid taxifolin and the seven main flavonolignans present in silymarin: silybin $A$ and $B$, isosilybin $A$ and $B$ (two diastereomeric pairs accounting for $50 \%$ of silymarin), silychristin, isosilychristin and silydianin. 

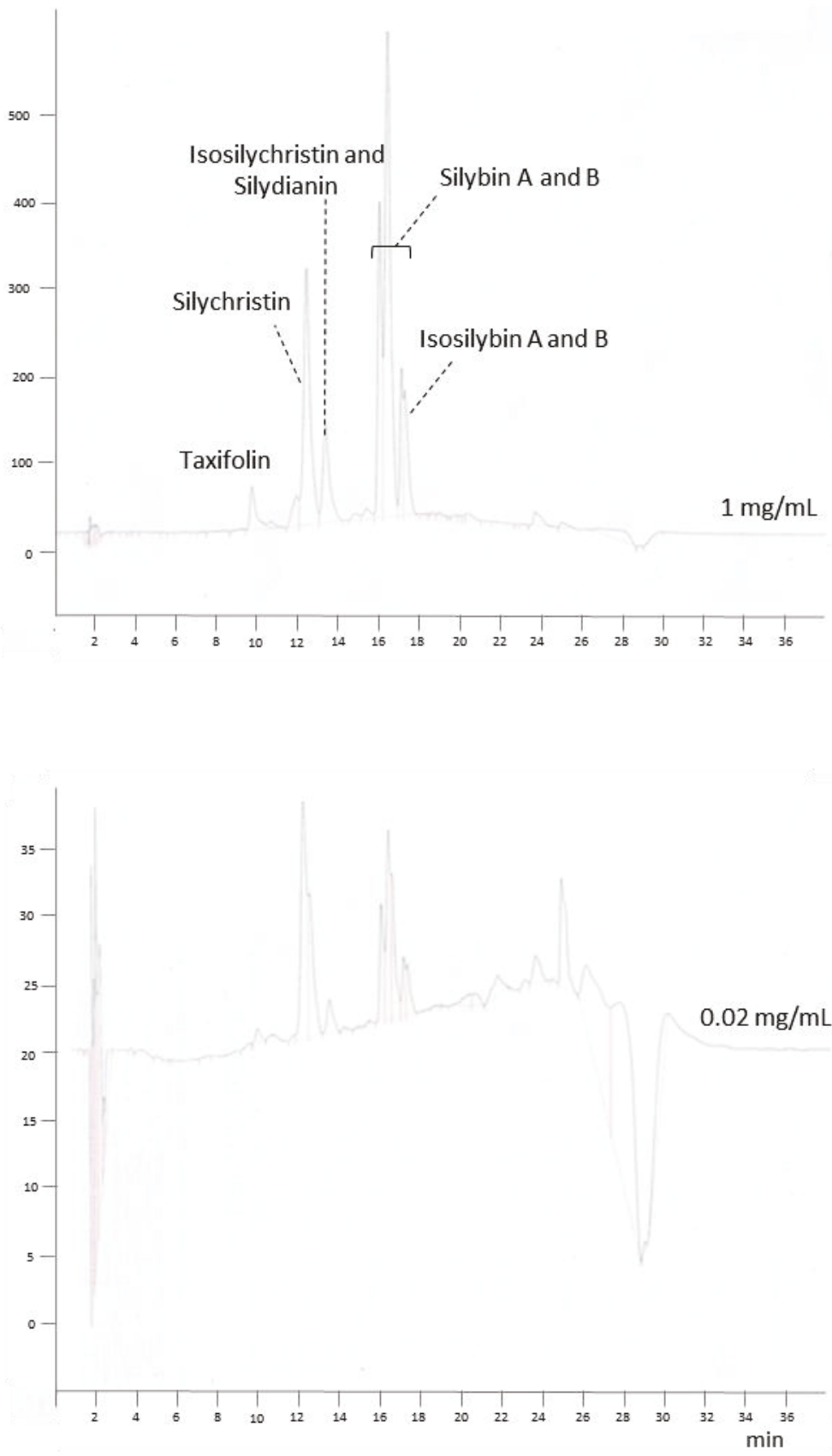

Fig. 2. Chromatographic profile of silymarin standard solutions at $1 \mathrm{mg} / \mathrm{mL}$ (top) and $0.02 \mathrm{mg} / \mathrm{mL}$ (bottom). 
(a)

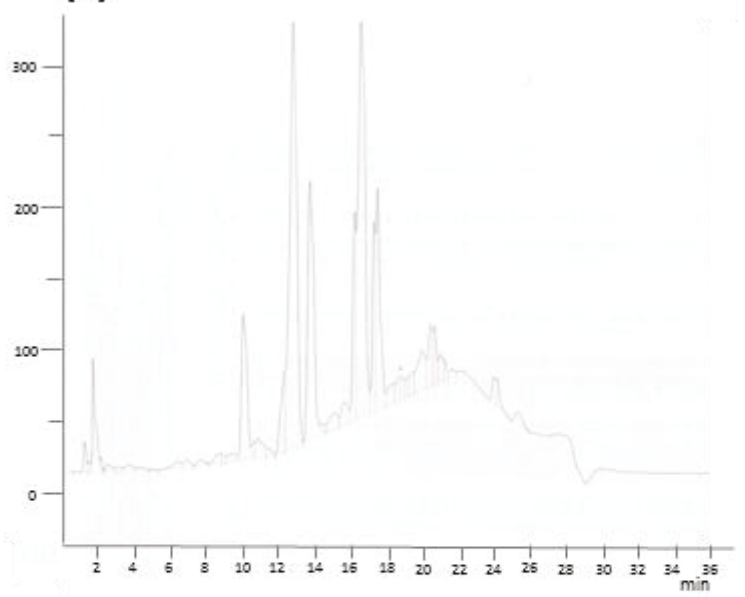

(b)

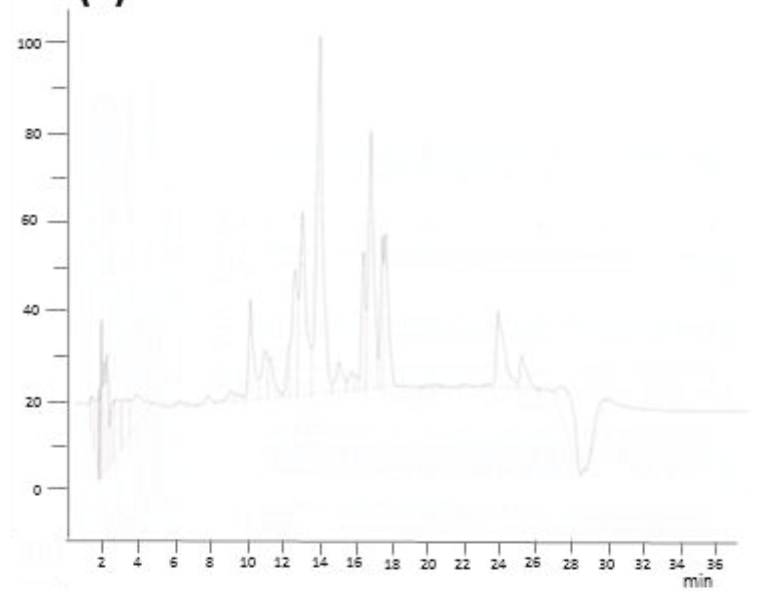

(c)

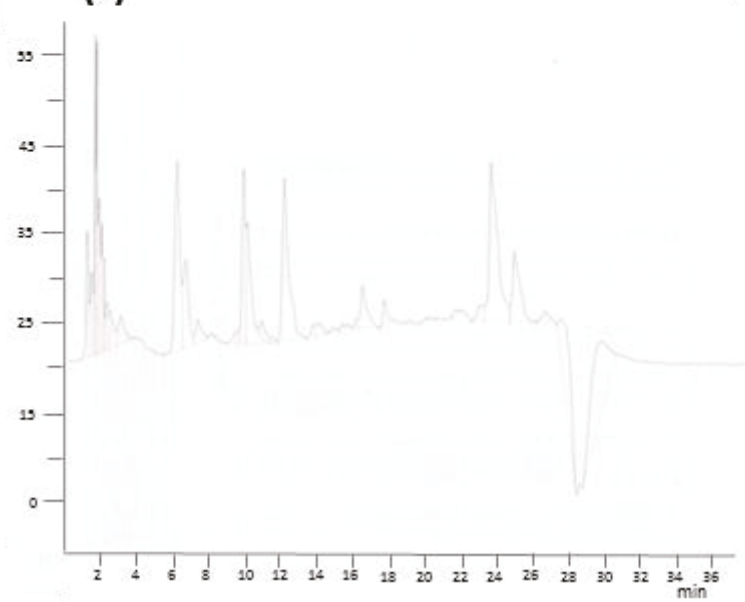

Fig. 3. HPLC chromatograms of samples (a) J, (b) E and (c) D. 